\title{
New Method of Paper Hydrophobization Based on Starch-cellulose-siloxane Interactions
}

\author{
Tomasz Ganicz, ${ }^{\mathrm{a}, *}$ Konrad Olejnik, ${ }^{\mathrm{a}}$ Krystyna Rózga-Wijas, ${ }^{\mathrm{b}}$ and Jan Kurjata ${ }^{\mathrm{b}}$ \\ A new method of paper hydrophobization was evaluated based on a \\ coating agent containing a water emulsion of triethoxymethylsilane with \\ standard starch solutions. The effects of different concentrations on the \\ hydrophobic properties of the resulting silicone-coated materials were \\ investigated using a penetration dynamics analyzer (PDA) and water \\ contact angle measurements. This study also examined the effects of the \\ applied coatings on the paper's tensile strength, tear index, roughness, air \\ permeance, and ISO brightness. Preliminary studies were conducted on \\ the molecular interaction mechanisms between the silicone agent and \\ starch modifiers, based on solid state nuclear magnetic resonance (NMR) \\ and scanning electron microscope (SEM) images.
}

Keywords: Alkoxysilane; Microparticles; Paper hydrophobization; Starch; Water emulsion

Contact information: a: Centre of Papermaking and Printing, Lodz University of Technology, Wolczanska 223, 90-924 Lodz, Poland; b: Centre of Molecular and Macromolecular Studies, Polish Academy of Sciences, Sienkiewicza 112, 90-363 Lodz, Poland; *Corresponding author: Tomasz.ganicz@ p.lodz.pl

\section{INTRODUCTION}

Natural materials based on cellulosic fibers are very popular and widely used because of their good mechanical and protective properties and low cost. They are also produced from renewable, recyclable, and biodegradable resources, making them attractive from an environmental point of view.

Paper products are materials of capillary-porous structure. Cellulosic fibers, which are the main component of this structure, are hydrophilic, giving paper good water absorption properties (Samyn 2013). In many cases, this behavior is unfavorable and has to be mitigated considering different paper qualities and end user demands. Excessive liquid absorption weakens paper's structure and may lead to poor printing quality, for example. Without sizing or hydrophobizing additives, paper does not have any barrier properties against water. Recently, several countries have made efforts, such as new laws, to limit the usage of single-use plastic products. As a result, there is growing interest in increasing paper's resistance towards liquids, which may allow increased production of single-use, environmentally friendly items (e.g., food containers, bottles, cups, and straws).

There are numerous methods for introducing hydrophobic properties to cellulose fiber-based materials. These include the use of formaldehyde-urea-, formaldehydemelamine-, or glyoxalated-polyacrylamide- (GPAM) based resins; polyethylenimine (PEI, polyaziridine); dialdehyde-modified starch; and amine-polyamide-epichlorohydrin copolymers (Au and Thorn 1995; Holik 2013). The most common sizing agents used in the paper industry to improve resistance to wetting are alkyl ketene dimer (AKD) and alkenyl succinic anhydride (ASA) (Hubbe 2007; Lindström and Larsson 2008). Barriers to liquids can also be easily achieved by coating the surface of the paper with paraffin or synthetic polymers, such as polyethylene and polypropylene, although this kind of 
treatment leads to non-biodegradable products (Au and Thorn 1995; Xu et al. 2002). Various natural and environmentally friendly components such as chitosan, carnauba wax, and whey-protein have been studied (Han and Krochta 2001; Despond et al. 2005), but they are either costly or inefficient.

Other promising hydrophobic agents are organic compounds containing silicon, such as chlorosilane and alkoxysilane condensates and derivatives; linear, branched, and modified polysiloxanes; and siloxane resins with reactive functional groups (Xie et al. 2010). Reactive silanes are especially recognized as efficient coupling agents that may be used for surface modification of natural fibers (Abdelmouleh et al. 2002). The environmental advantage of siloxane-based coatings over those based on other synthetic polymers or resins is their ability to decompose to naturally occurring silicate microparticles (fine sand), not to volatile organic compounds. In general, four interaction mechanisms between silanes and natural fibers have been reported (Xie et al. 2010): hydrolysis of silanes in the presence of water and catalyst, physical adsorption of resulting silanols to the hydroxyl groups of natural fibers by hydrogen bonds, thermal rearrangement of hydrogen bonds between silanols and the hydroxyl groups of fibers into the covalent $\mathrm{Si}-\mathrm{O}-\mathrm{C}$ bonds, and direct formation of -Si-O-C bonds between silanes and fibers.

Most of the silicone or siloxane hydrophobizing agents that have been considered (Cappelletto et al. 2012; Missoum et al. 2013) or made available commercially (Coatings2Go 2014) are based either on ethanol solutions of aminosilanes and ethoxysilanes or on chlorosilanes. In recent studies, systems can also be found based on the deposition of silicate nanoparticles (Le et al. 2016) or surface-silylated nanocellulose fibers (Korhonen et al. 2011; Song and Rojas 2013). Yet another method of giving paper hydrophobic properties utilizes resins containing silicon, which form silicate nanoparticles in situ from tetraethoxysilane and hexadecyltrimethoxysilanes on the surfaces of the cellulose fibers. These are then functionalized with fluoroalkyl chlorosilanes (Luna et al. 2015). Notably, hydrophobizing agents based on nanosilica nanoparticles produce effective "superhydrophobic" surfaces, if applied in a very clean and controlled environment (Ogihara et al. 2012; Oyola-Reynoso et al. 2015, 2016).

Each of the aforementioned methods has certain disadvantages. Aminosilane- and chlorosilane-based agents are hydrolytically unstable and emit ammonia or hydrochloric acid when exposed to water. They must therefore be stored and applied in a moisture-free environment. Alkoxysilane- and silica particle-based solutions must be applied in a complicated multistep procedure to produce the desired effect. From the point of view of the industrial practice, hydrophobizing agents that cannot be applied in a one-step process in high humid conditions would require very expensive changes to machinery and technology. Moreover, all the methods use solvents classified as volatile organic compounds (VOCs), which are not suitable for industrial paper production due to safety and environmental risks.

The main aim of this study was to develop a new, efficient, and commercially viable silicon-based hydrophobic agent which can be applied without substantial changes to the currently used paper production technologies, which is based on water solutions of cellulose fibers and starch. Chemicals that change the properties of mass-produced paper are added to the pulp either just before it is poured into the forming-machine or to the starch solution just before being fed to the sizing press.

A water-based hydrophobizing agent, originally used for industry materials such as sand and concrete, was reported recently by the authors and others (Kurjata et al. 2013; Wojciechowski et al. 2014; Kurjata et al. 2018). However, due to the highly porous nature 
of paper, it could not be used without considerable changes to both the chemical composition and the application method. This paper presents an approach to paper hydrophobization using a mixture of a water-based silane compound and starch, which could be used for size press application.

\section{EXPERIMENTAL}

\section{Materials and Methods}

Chemicals

Methyltriethoxysilane (98\%, ABCR GmbH, Karlsruhe, Germany), poly(vinyl alcohol) $(\mathrm{PVOH})\left(\right.$ Mowiol ${ }^{\circledR} 8-88$, Sigma-Aldrich, St. Louis, MO, USA, molar mass = 6.7 $\times 10^{4} \mathrm{~g} / \mathrm{mol}$, reagent grade), commercial wheat starch (C*Flex 20002, Cargill, Incorporated, Minneapolis, MN, USA, containing $31.16 \mathrm{wt} \% \pm 0.15 \mathrm{wt} \%$ amylose, 0.24 $\mathrm{wt} \% \pm 0.02 \mathrm{wt} \%$ lipids, and $0.29 \mathrm{wt} \% \pm 0.01 \mathrm{wt} \%$ proteins), and sodium C12-15 pareth sulfate solution (Sulforokanol L-327, Silikony Polskie Ltd., Nowa Sarzyna, Poland) were used in the research. Demineralized water was obtained by reverse osmosis (RO-5, Aquafilter Europe Ltd., Lodz, Poland) from tap water.

\section{Preparation of methyltriethoxysilane emulsion in water (SIL)}

This is a modification of original method of preparation developed by Kurjata et al. (2018). Stock solutions of $10 \mathrm{wt} \%$ of PVOH in water (solution A) and $2 \mathrm{wt} \%$ solution of sodium C12-15 pareth sulfate in demineralized water (solution B) were prepared separately. Then, 10 parts by weight of solution A were diluted with 20 parts by weight of demineralized water. This mixture was homogenized for $5 \mathrm{~min}$ using a high-speed Heidolph Silent Crusher M homogenizer (Heidolph Instruments $\mathrm{GmbH}$ \& Co. KG, Schwabach, Germany) set to $14,000 \mathrm{rpm}$, after which 50 parts by weight of methyltriethoxysilane were introduced with vigorous mixing for 4 min to yield an emulsion. Subsequently, 20 parts by weight of solution B were added to the mixture, which was homogenized for $5 \mathrm{~min}$ at 9,000 rpm. The resulting final emulsion was stable and did not separate after $15 \mathrm{~min}$ of centrifuging at 3,000 rpm. The emulsion contained $50 \mathrm{wt} \%$ of silane/siloxane material, composed of triethoxymethylsilane and the oligomeric products of its reaction with water.

\section{Preparation of starch mixture (ST)}

A mixture of wheat starch $(10 \mathrm{~g})$ and $\mathrm{NaOH}(0.5 \mathrm{~g})$ in $250 \mathrm{~mL}$ of demineralized water was stirred at $60{ }^{\circ} \mathrm{C}$ for $1 \mathrm{~h}$. The resulting transparent viscous solution was used with no further purification.

\section{Preparation of coating mixtures (ST:SIL)}

The $50 \mathrm{wt} \%$ silane/siloxane emulsion (SIL) and starch solution (ST) were mixed in the proportions shown in Table 1 for 5 min using a homogenizer $(5000 \mathrm{rpm})$ at room temperature. The resulting opaque white microemulsion was used immediately following preparation. 
Table 1. Compositions of Coating Mixtures

\begin{tabular}{|c|c|c|c|c|}
\hline Mixture & $\begin{array}{c}\text { Volume of } \\
\text { Silane Emulsion } \\
(\text { SIL) }(\mathrm{mL})\end{array}$ & $\begin{array}{c}\text { Volume of } \\
\text { Starch } \\
\text { Solution }(S T) \\
(\mathrm{mL})\end{array}$ & $\begin{array}{c}\text { Volume } \\
\text { Percentage of } \\
\text { Silane Emulsion* } \\
(\text { vol\%) }\end{array}$ & $\begin{array}{c}\text { Silane/Siloxane } \\
\text { Material (wt\%) }\end{array}$ \\
\hline ST & 0 & 50 & 0 & 0 \\
\hline SIL & 50 & 0 & 100 & 50 \\
\hline ST:SIL 100:10 & 10 & 100 & 9.09 & 4.5 \\
\hline ST:SIL 100:25 & 25 & 100 & 20 & 10.0 \\
\hline ST:SIL 100:50 & 25 & 50 & 33.33 & 16.7 \\
\hline ST:SIL 100:100 & 50 & 50 & 50 & 25 \\
\hline
\end{tabular}

* Calculated as $($ SIL / $(S I L+S T)) \times 100 \%$

\section{Base paper preparation}

Commercial, bleached softwood pine kraft pulp (BSK) was used to prepare laboratory handsheets. The parameters of the pulp were as follows: an initial moisture content of $93.78 \%$, an $\alpha$-cellulose content of $86.6 \%$, a degree of polymerization of 1081 , and a Schopper-Riegler value of SR-12. Pulp samples were prepared according to the standard procedure described in ISO 5263-1 (2004). Laboratory handsheets with an average weight of $70 \mathrm{~g} / \mathrm{m}^{2}$ were formed in a Rapid-Köthen (Model 2004, Labor-Meks, Lodz, Poland) apparatus according to ISO 5259-2 (2001). The laboratory sheets were used as the base paper for subsequent coatings.

\section{Coating paper surface}

Coating mixtures were applied to the surfaces of the paper samples using an automatic coater (Control Coater, TUL, Lodz, Poland) and a standard Mayer rod No. 3 (Kbar) at a speed of $16 \mathrm{~cm} / \mathrm{s}$, yielding a wet film thickness of $24 \mu \mathrm{m}$. The coated papers were dried using a laboratory rotary drum dryer (Type 89, Mechanika Praha, Czech Republic) at a temperature of $100{ }^{\circ} \mathrm{C} \pm 2{ }^{\circ} \mathrm{C}$. The arithmetic average weights of the base handsheets and coated handsheets are listed in Table 2.

Table 2. Average Masses of Handsheets

\begin{tabular}{|c|c|c|c|c|}
\hline Sample & $\begin{array}{c}\text { Average Mass of } \\
\text { Base Sheets }(\mathrm{g})\end{array}$ & $\begin{array}{c}\text { Average Mass of } \\
\text { Coated Sheets } \\
(\mathrm{g})\end{array}$ & $\begin{array}{c}\text { Mass of Coating } \\
(\mathrm{g})\end{array}$ & $\begin{array}{c}\text { Increase of } \\
\text { Mass }(\%)\end{array}$ \\
\hline Reference & 1.99 & - & - & - \\
\hline SIL & 1.98 & 2.17 & 0.19 & 9.60 \\
\hline ST & 2.00 & 2.06 & 0.06 & 3.00 \\
\hline ST:SIL 100:10 & 1.98 & 2.06 & 0.08 & 4.04 \\
\hline ST:SIL 100:25 & 2.01 & 2.11 & 0.10 & 4.97 \\
\hline ST:SIL 100:50 & 1.99 & 2.13 & 0.14 & 7.03 \\
\hline ST:SIL 100:100 & 1.98 & 2.16 & 0.18 & 9.09 \\
\hline Average mass calculated as arithmetic mean of all handsheets used for studies. \\
\hline
\end{tabular}

\section{Analytical Techniques}

\section{Mechanical and surface paper properties}

The paper samples were conditioned according to the ISO 187:1990 standard. The following properties were determined in accordance with the appropriate ISO standards: tensile index and elongation (ISO 1924-2:2008), Elmendorf tear resistance (ISO 
1974:1990), Bendtsen surface roughness (ISO 8791-2:1990), Bendtsen air permeance (ISO 5636-3:1992), and ISO brightness (ISO 2470-1:2016).

\section{Contact angles}

A PGX goniometer (Testing Machines, Inc., New Castle, DE, USA) was used to measure the contact angles. Tests were performed according to the TAPPI T 458 (2004) standard method (static procedure).

\section{Water penetration dynamics}

Water penetration dynamics were studied using a penetration dynamics analyzer (PDA) (Module S 05, Emtec Electronic GmbH, Leipzig, Germany). The handsheets were cut into three samples, each $3 \mathrm{~cm} \times 7 \mathrm{~cm}$. Measurements were performed separately for each sample in demineralized water at $20{ }^{\circ} \mathrm{C}$, following the standard procedure described by the manufacturer. The result was an arithmetic average value calculated from the series of measurements.

\section{Water absorptiveness}

Water absorptiveness studies were performed using extended Cobb test (ISO 535:2014). Cobb tests were conducted for the following exposure times to water (in minutes): 2, 30, 60, 120, and 1200 .

\section{Nuclear magnetic resonance (NMR) studies}

Samples for NMR studies were prepared as follows: First, $0.5 \mathrm{~g}$ of starch (approximately $2.5 \times 10^{-3}$ mol of $-\mathrm{CH}_{2} \mathrm{OH}$ groups) was mixed with $12 \mathrm{~g}$ of water and 0.02 $\mathrm{g}$ of $\mathrm{NaOH}$ at $60{ }^{\circ} \mathrm{C}$ for $1 \mathrm{~h}$. The mixture was then cooled to room temperature. Next, 0.98 $\mathrm{g}$ of silane/siloxane emulsion (50 wt $\%$ ) (SIL) $\left(2.75 \times 10^{-3} \mathrm{~mol}\right.$ of triethoxymethylsilane) was added, and the solution was stirred for $24 \mathrm{~h}$. The mixture was then boiled at $100{ }^{\circ} \mathrm{C}$ for $2 \mathrm{~h}$, to evaporate the water. The solid product was dried under a vacuum $(0.01 \mathrm{~mm} \mathrm{Hg})$ at room temperature for $6 \mathrm{~h}$.

The ${ }^{13} \mathrm{C}$ and ${ }^{29} \mathrm{Si}$ solid state NMR studies were performed using a Bruker DSX-300 spectrometer (Bruker, Billerica, MA, USA), with samples placed in 4-mm zirconia rotors. The ${ }^{13} \mathrm{C}$ cross polarization (CP) / magic angle spinning (MAS) NMR spectra were obtained at $75.47 \mathrm{MHz}$ using $\mathrm{CP}$ and MAS at a rate of $8 \mathrm{kHz}$, applying a $90^{\circ}$ pulse and $6.0 \mathrm{~s}$ pulse delays. The ${ }^{29} \mathrm{Si} \mathrm{CP} / \mathrm{MAS}$ NMR spectra were recorded at $59.63 \mathrm{MHz}$, with $90^{\circ}$ pulses, 6.0 $\mathrm{s}$ pulse delays, and $3 \mathrm{~ms}$ contact times. The samples were placed in $4.0-\mathrm{mm}$ zirconia rotors and spun at a rate of $8 \mathrm{kHz}$.

\section{Scanning electron microscopy (SEM)}

Scanning electron microscopy images of the paper samples were taken using a JSM-5500 LV (JEOL Ltd., Tokyo, Japan) scanning electron microscope. The original, standard conditioned (ISO 187) handsheets were cut into small samples. Their surfaces were covered with a nanolayer of gold using a standard vapor deposition process. Images of several areas on the surfaces of each sample were taken separately.

\section{Starch chemical composition}

The native starch was analyzed as received from the vendor, while the starch samples were isolated from the mixtures (ST, ST:SIL 100:10, and ST:SIL 100:100) by freeze-drying as described elsewhere (Rosicka - Kaczmarek et al. 2016). The total lipid 
content was determined by the Soxhlet-Weibull method, with acid hydrolysis and extraction with petroleum ether (Rosicka - Kaczmarek et al. 2016). The protein content was measured by the Kjeldahl method, according to the nitrogen procedure of the American Association of Cereal Chemists (AACC 46-12.01 1983). The total amylose content was determined by colorimetric concentration measurement of its blue polyiodide complex (Morrison and Laignelet 1983). All results were expressed on a dry weight basis (Table 4).

\section{RESULTS AND DISCUSSION}

This study proposed a new formula and method for the application of alkoxysilanes emulsified with starch and water for the hydrophobization of paper. The method used a starch solution ( $\mathrm{pH}$ of $10.4,3.5 \%$ to $4 \%$ conc.) that is typically applied on industrial sizing presses in numerous paper-forming machines. The siloxane component, composed of a water emulsion of triethoxymethylsilane stabilized by PVA and sodium C12-15 pareth sulfate detergent (SIL), was originally developed for the hydrophobization of building industry materials containing silicate, such as sand and concrete (Kurjata et al. 2018).

The molecular mechanism by which sand and ethoxysilanes interact is based on reactions with $\mathrm{Si}-\mathrm{OH}$ groups available on the surfaces of silicates (Kurjata et al. 2013). Thus, it could be assumed that a similar process occurs in the case of the $-\mathrm{CH}_{2}-\mathrm{OH}$ moieties present in the cellulose fibers that form both the surface of the paper and the walls of the pores, as has been demonstrated in numerous studies (Xie et al. 2010). To obtain better stability, penetration, and compatibility with starch, as well as to decrease costs, the concentrations of all the chemicals in the siloxane component (SIL) were decreased to minimal but still working levels. For practicality, the $\mathrm{pH}$ and the concentration of the starch solution (ST) were kept constant. The only studied variable was therefore the proportion of starch solution (ST) to the silane/siloxane emulsion (SIL) (Table 1).

\section{Preparation and Application of Coating Mixtures}

The studied hydrophobizing agent was a stable emulsion of silanes and siloxanes in water (SIL), which could be stored for several months. It consisted of a mixture of original triethoxymethylsilane and the products of its reaction with water: methylsilanols and their oligomers. The substrate and intermediate products of condensation were in dynamic equilibria, which could be easily shifted by changing the $\mathrm{pH}$ of the system, as it was already in-depth investigated in our previous studies (Rózga-Wijas et al. 2010; Kurjata et al. 2013). The current method of preparation of initial emulsion (SIL) was partially based on the authors' previous knowledge of silane/siloxane equilibria as well as trial and error experimental work. After homogenization with a water solution of starch (ST), the mixture formed a white suspension with low viscosity. The stability of this mixture was not investigated, as it was used immediately following preparation. However, some precipitation was observed after $24 \mathrm{~h}$ of storage. However, for at least the duration of the coating procedure (approximately $1 \mathrm{~h}$ ), it remained stable. The method of application approximated the technological processes that occur in starch presses and the final drying sections of contemporary paper-forming machines. After applying the coatings, the average weight of the handsheets increased by $3 \%$ to $9.6 \%$ (Table 2 ). 


\section{Hydrophobic Properties}

The hydrophobic properties of the handsheets were studied using two methods. Static measurements of the contact angles of water drops placed on the surface of the paper were performed according to the TAPPI T 458 (2004) standard. Water penetration dynamics were analyzed using a PDA. Both methods were performed for reference samples of untreated handsheets, papers coated with pure silane/siloxane hydrophobizate (SIL), pure starch solution (ST), and four different starch-hydrophobizate mixtures (ST:SIL) in the proportions shown in Table 1.

The drops of water were completely absorbed within $15 \mathrm{~s}$ to $40 \mathrm{~s}$ by the sample volumes of the reference handsheets, as well as by the paper samples coated with pure hydrophobizate (SIL) and with pure starch solution (ST), making it impossible to measure the contact angles under static conditions. The greatest time for complete absorption was observed for the samples treated with pure hydrophobizate (SIL) (40 s). The shortest complete absorption time was observed for the untreated reference samples (15 s).

The findings were different for the handsheets coated with the ST:SIL mixtures. Even in the sample treated with the lowest amount of silane/siloxane hydrophobizate (ST:SIL 100:10), the water drops were not absorbed at all and remained on the surface until they evaporated. Usually, the contact angles stabilized after $15 \mathrm{~s}$. The angles were in the range of $100.4^{\circ}$ to $113.9^{\circ}$ and increased slightly as the amount of silicon hydrophobizate in the coating mixture increased. Quite satisfactory results were obtained with a mixture containing only 9.09 vol\% of hydrophobizate (ST:SIL 100:10), as shown in Table 3.

Table 3. Static Contact Angles as Measured by the TAPPI T 458 (2004) Method

\begin{tabular}{|c|c|c|}
\hline Sample & $\begin{array}{c}\text { Contact Angle } \\
\text { after } 30 \mathrm{~s}\left({ }^{\circ}\right) \\
\text { Unmeasurable }\end{array}$ & No stable drop \\
\hline Reference & Unmeasurable & No stable drop \\
\hline SIL & Unmeasurable & No stable drop \\
\hline ST & 100.4 & \\
\hline ST:SIL 100:10 & 100.5 & \\
\hline ST:SIL 100:25 & 108.4 & \\
\hline ST:SIL 100:50 & 113.9 & \\
\hline
\end{tabular}

The PDA method allows real-time assessment of the penetration of the liquid in which the sample is immersed. If the material has a surface barrier, there is a peak in the measured signal, which then decreases due to complex changes in the dispersal of air within the paper structure, due to the appearance of microbubbles, swelling, and general mass wetting. Measurements were performed using a PDA according to the manufacturer's instructions for three different samples of each type of paper handsheet separately. The results of the PDA measurements are presented in Fig. 1.

Neither the reference samples nor the paper coated with the pure starch solution (ST) exhibited any barrier properties towards water. Complete wetting occurred between 3 $\mathrm{s}$ and $10 \mathrm{~s}$ after immersion in water. The SIL samples coated with the silane/siloxane emulsion only, despite having been found previously to have a very limited surface barrier, moistened in their mass much more slowly and to a much lesser degree than the reference samples and the paper coated with starch only. Complete saturation occurred after $25 \mathrm{~s}$ to $30 \mathrm{~s}$. 

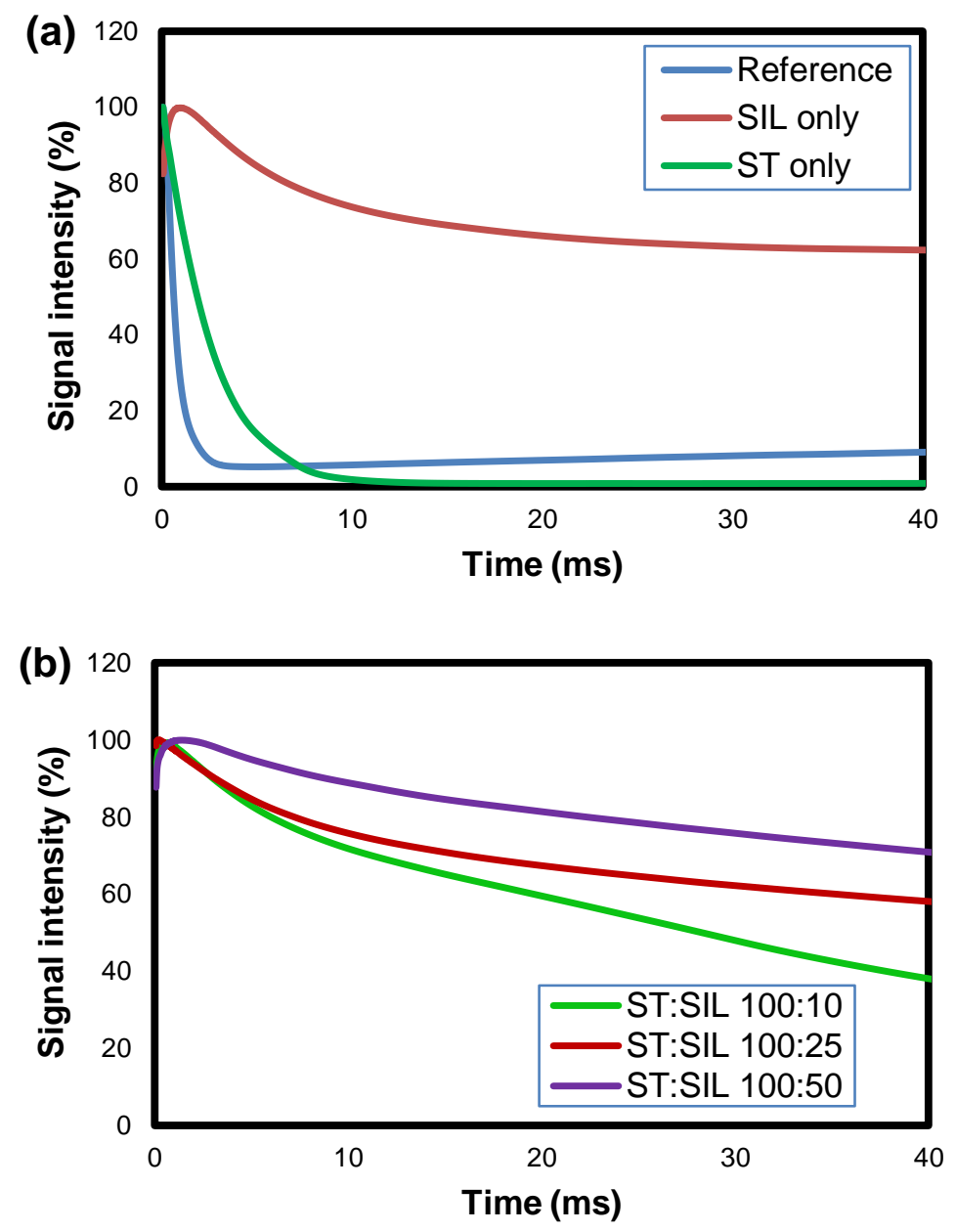

Fig. 1. Penetration dynamics analysis of samples: (a) reference sample, starch only (ST), and silicone hydrophobizate only (SIL); (b) ST:SIL 100:10, ST:SIL 100:25, and ST:SIL 100:50

The paper coated with the ST:SIL 100:10 mixture exhibited a lower volume barrier than the samples treated with the pure silane/siloxane hydrophobizate (SIL), but it was still slightly higher than the volume barrier presented by the paper coated with the pure starch solution (ST). Much greater hydrophobicity was observed for the samples coated with ST:SIL mixtures with at least 20 vol\% of siloxane hydrophobizate (ST:SIL 100:25). Even better hydrophobic properties were observed for the samples coated with ST:SIL 100:25, ST:SIL 100:50, and ST:SIL 100:100. However, the difference between ST:SIL 100:25 and ST:SIL 100:100 was negligible. Obtained results suggest that 20 vol\% concentration of silane/siloxane hydrophobizate in a $4 \%$ solution of starch is optimal.

In order to study durability of hydrophobic properties in prolonged contact with water, the extended Cobb absorptiveness measurements were performed for reference samples of untreated handsheets and papers coated with starch-hydrophobizate mixture (ST:SIL 100:50). The results are given in Table 4. For reference untreated samples, the water absorption was very high, over $100 \%$ of their dry weights. After prolonged time of measurement $(20 \mathrm{~h})$ the reference samples lost their mechanical integrity. Therefore, it was impossible to remove them in one piece from the apparatus. For coated sheets the amount of water absorbed did not exceed 50\% of their initial weight even after $20 \mathrm{~h}$ of contact with water. The opposite side of the coated sheets remained dry in all cases. 
The coated samples after Cobb tests were dried by keeping them exposed to air in standard condition for $48 \mathrm{~h}$ in order to examine their surface hydrophobic properties by water-drop contact angles. The longer the contact with water during Cobb tests, the lower the contact angles. However, even after a very long time of contact $(20 \mathrm{~h})$, the surfaces of samples still exhibited reasonably good hydrophobic properties.

Table 4. Average Increase of Weights due to Water Absorbed (Extended Cobb test) and Static Contact Angles of samples of ST:SIL 100:50 as Measured by the TAPPI T 458 (2004) Method

\begin{tabular}{|c|c|c|c|}
\hline Time (min) & $\begin{array}{c}\text { \% of Increase of } \\
\text { Weights due to } \\
\text { Water Absorption } \\
\text { by Base Sheets - } \\
\text { Ref. }\end{array}$ & $\begin{array}{c}\text { \% of Increase of } \\
\text { weights due to Water } \\
\text { Absorption by Coated } \\
\text { Sheets - sample } \\
\text { ST:SIL 100:50 }\end{array}$ & $\begin{array}{c}\text { Contact Angle of ST:SIL } \\
100: 50\end{array}$ \\
\hline 2 & 90.43 & 10.03 & 108.2 \\
\hline 30 & 95.46 & 42.10 & 101.4 \\
\hline 60 & 103.94 & 42.59 & 100.7 \\
\hline 120 & 105.93 & 43.44 & 100.3 \\
\hline $1200(20$ h) & Unmeasurable & 49.17 & 98.7 \\
\hline Average increase calculated as arithmetic mean of 3 samples used for studies \\
\hline \multicolumn{4}{|r}{} \\
\hline
\end{tabular}

\section{NMR and SEM Analyses of Molecular Hydrophobization Mechanisms}

This section discusses preliminary results regarding the molecular mechanism of paper hydrophobization by the starch-silane/siloxane mixtures. The main research question was whether the hydrophobic effect was due to reactions between silanol groups ( $\mathrm{Si}-\mathrm{OH})$ and hydroxyl groups $\left(\mathrm{CH}_{2}-\mathrm{OH}\right)$ from the cellulose and starch or due to other physiochemical processes.

In general, the condensation of silanol groups that occurs on silicate surfaces requires extreme conditions, such as high temperatures, long reaction times, or special organic solvents (Musso et al. 2015). Condensation with cellulose hydroxyl groups can be even more difficult. For example, in order to silylate cellulose nanofibers by dodecyldimethylchlorosilane under dry, hot toluene in the presence of imidazole, it is necessary to continue the reaction for over $14 \mathrm{~h}$ (Pei et al. 2010). Similarly, harsh conditions are needed to partially silylate the surfaces of cellulose whiskers with alkyldimethylchlorosilanes (Goussé et al. 2002).

In contrast, there have been numerous studies describing the hydrophobization of cellulosic materials with alkoxysilanes and aminosilanes under relatively mild conditions (Xie et al. 2010). This is usually driven by a low $\mathrm{pH}$, sol-gel process leading to in situ preparation of silsesquioxane networks, which may or may not be covalently bonded to the surfaces of the cellulose fibers (Saini et al. 2016; Laitinen et al. 2017; Khanjanzadeh et al. 2018).

Silanols can be adsorbed on the surfaces of starch micelles in a water emulsion by hydrogen bonds, by covalent $\mathrm{Si}-\mathrm{O}-\mathrm{C}$ bonds formed in the reactions of silanols with $\mathrm{C}-\mathrm{OH}$ groups, or simply by van der Waals forces. In a basic water solution, silanols present in the mixture as a very reactive species can easily condense with one another, forming a $\mathrm{Si}-\mathrm{O}$ Si-bonded cross-linked 3D silsesquioxane network with dominant, non-polar $\mathrm{Si}-\mathrm{CH}_{3}$ groups on the surface (Rózga-Wijas et al. 2010). In this study's siloxane-starch mixtures, there was also the issue of competing reactions between silanols and $-\mathrm{CH}_{2} \mathrm{OH}$ groups from 
the starch or cellulose molecules, which, to the authors' knowledge, has not been studied previously.

To determine which of these processes was dominant, preliminary solid-state ${ }^{29} \mathrm{Si}$ and ${ }^{13} \mathrm{C}$ NMR studies of starch treated with triethoxymethylsilane were performed. A higher proportion of triethoxymethylsilane to the starch in NMR samples in comparison with the original ST:SIL mixtures was used in order to obtain strong enough signals, especially in the case of ${ }^{29} \mathrm{Si}$ NMR spectra. The ${ }^{13} \mathrm{C}$ CP/MAS NMR analysis showed a characteristic peak at $-3.07 \mathrm{ppm}$, which could be attributed to the methylsilyl group in the silsesquioxane network. There were resonance lines at $102.48 \mathrm{ppm}, 81.46 \mathrm{ppm}, 72.26 \mathrm{ppm}$, and $61.31 \mathrm{ppm}$, which were assigned to the carbons of the methylene and methine groups in the glucose ring (Fig. 2b). Examples of the ${ }^{29} \mathrm{Si}$ MAS NMR spectra of the modified starch are shown in Fig. 2a. The first peak, at $-66.18 \mathrm{ppm}$, corresponded to the type $\mathrm{T}^{3}$ silicon atom $\left(\mathrm{CH}_{3} \mathrm{Si}(\mathrm{O}-)_{3}\right)$, and the second, at $-56.64 \mathrm{ppm}$, corresponded to a type $\mathrm{T}^{2}$ silicon atom, $\mathrm{CH}_{3} \mathrm{Si}(\mathrm{OH})(\mathrm{O}-)_{2}$. That no signal was attributed to silicon type $\mathrm{T}^{1}\left(\mathrm{CH}_{3} \mathrm{Si}(\mathrm{OH})_{2}(\mathrm{O}-)\right)$ groups, while an intense $\mathrm{T}^{3}$ signal was identified, shows that the silanol groups underwent self-condensation with relatively high yield, probably leading to the formation of branched and crosslinked structures. However, the presence of a weak but still clearly visible signal from the $\mathrm{T}^{2}$ groups suggested that the mixture contained a small amount of reactive $\mathrm{Si}-\mathrm{OH}$ moieties, which may remain active when the starch-siloxane mixture is applied to paper, especially during drying at $100{ }^{\circ} \mathrm{C}$.

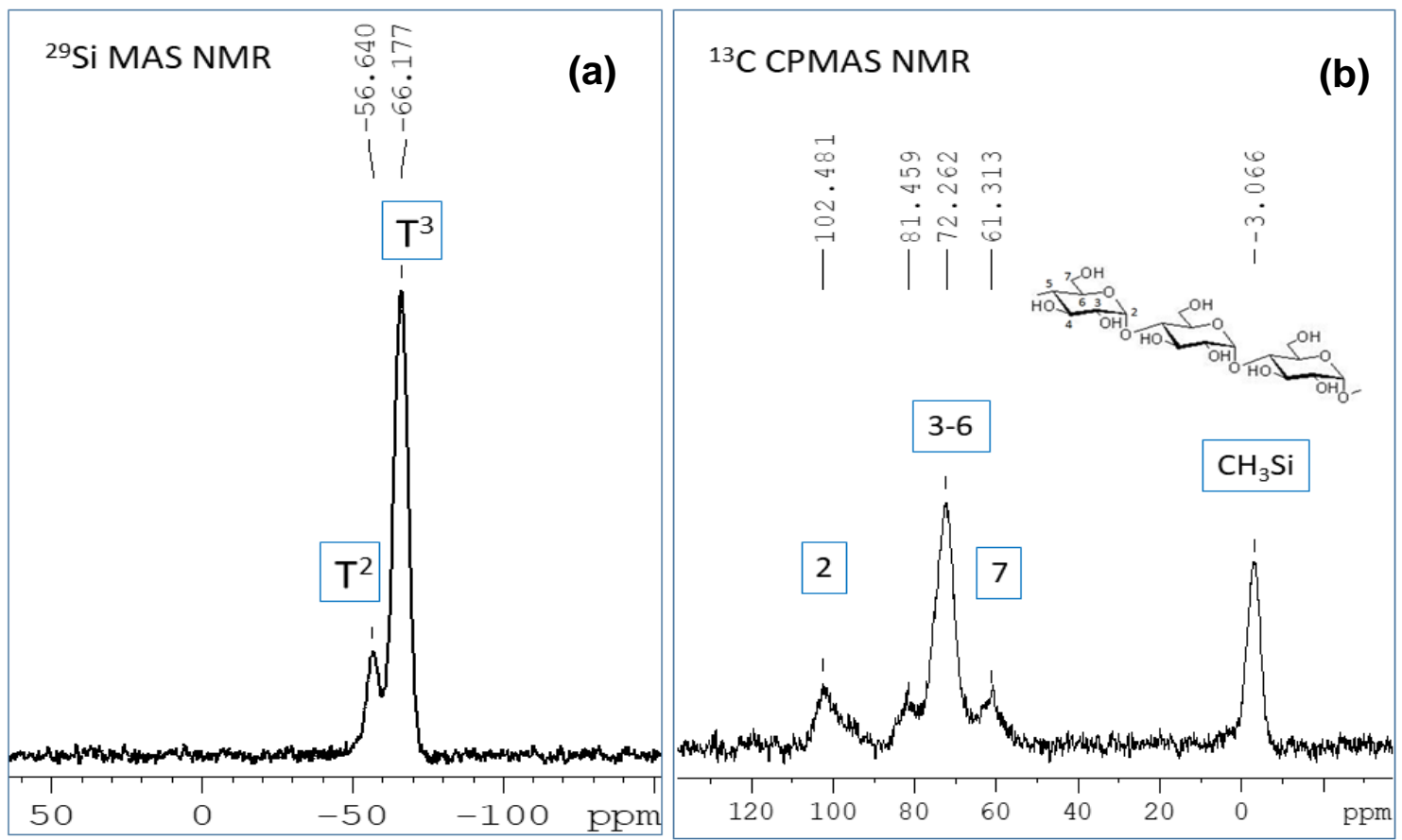

Fig. 2. (a) ${ }^{29} \mathrm{Si}$ and (b) ${ }^{13} \mathrm{C}$ MAS NMR spectra of the modified starch obtained by hydrolytic polycondensation of methyltriethoxysilane in a base aqueous solution, using PVA and sodium C12-15 pareth sulfate as surfactants. $\mathrm{T}^{2}=\mathrm{CH}_{3}-\mathrm{Si}(\mathrm{OH})(\mathrm{O}-)_{2}, \mathrm{~T}^{3}=\mathrm{CH}_{3}-\mathrm{Si}(\mathrm{O}-)_{3}$

During the self-condensation of silanols, they may simultaneously become grafted to the surfaces of starch micelles via the reaction of unreacted $\mathrm{Si}-\mathrm{OH}$ moieties with $\mathrm{CH}_{2}$ $\mathrm{OH}$ groups, leading to the formation of Si-O-C bonds. According to the literature, this 
process is supported by a network of hydrogen bonds and, under acidic conditions $(\mathrm{pH}=$ 4), has been observed in solid-state NMR studies for hexadecyltrimethoxysilane (Wei et al. 2016) and aminopropyltriethoxysilane (Khanjanzadeh et al. 2018). The expected resonance signals in the ${ }^{29} \mathrm{Si}$ MAS NMR spectrum, which might have shown the existence of compounds containing Si-O-C bonds, were not observed in this analysis. Therefore, in this case, it seemed that the dominant process was self-condensation of silanols, leading to the formation of microparticles made of siloxane material only, with some unreacted Si$\mathrm{OH}$ groups still present on the surface.

This hypothesis was supported by comparative SEM studies of the coatings applied to the paper handsheets. The SEM images shown in Fig. 3 were recorded for the reference sample, for samples coated with starch only, for samples treated with the water emulsion of triethoxymethylsilane only, and for several samples treated with starch-silane/siloxane mixtures.

Taking into account that the reference handsheets had a porous structure, it seems that in order to achieve good water barrier properties the pores must be also blocked in order to avoid capillary effects, which might occur even if the surface of the fibers is hydrophobic.

In the samples coated with starch-siloxane mixtures, regular, spherical particles were clearly seen scattered on the paper surface. The particles on the ST:SIL 100:25 sample had smaller diameters (approximately $200 \mathrm{~nm}$ ) than those on the sample treated with ST:SIL 100:50 (approximately $500 \mathrm{~nm}$ ). The particles were randomly and non-uniformly distributed on the paper surfaces, with a strong tendency to gather in niches and irregular pores. However, they were also often present on the tops of the fibers. Assuming that the best hydrophobization effect is achieved when there is a sufficient average density of silicate particles on the surface of the sample, the best proportion of starch solution to siloxane hydrophobizate was observed for ST:SIL 100:25. With less than $20 \%$ of silane/siloxane emulsion, there were not enough particles, and too few pores were closed. Meanwhile, with a greater proportion there were more particles in the niches but not many more on the tops of the fibers.

In the case of samples treated with SIL only, one could observe very few silicate microparticles on the surface of fibers - much less than for any ST:SIL samples. The amount of the microparticles was probably not enough to fill both the pores and be present on the surface. Samples sized by starch solution only (ST) also did not exhibit good barrier properties. Although, the pores were clogged, water could still penetrate the samples, probably due to complete lack of surface hydrophobicity.

The hypothesis regarding the absence of direct reactions between the starch and siloxane components was also supported by determination of the chemical composition of starch samples isolated from coating mixtures. The differences in the total amounts of lipids, proteins, and amylose in all starch samples were within experimental error (Table 4). If amylose or amylopectin had reacted with siloxanes, forming insoluble particles, it would have affected their relative concentrations in starch isolated from the mixtures.

According to recent literature (Castellano et al. 2004; Rutter and Hutton-Prager 2018), in order to obtain covalent bonds between silanols and hydroxy groups from cellulose, relatively high temperatures (over $110^{\circ} \mathrm{C}$ ) and long curing times are required. It does not seem to be likely in this case, where the coatings were dried for $3 \mathrm{~min}$ at $100^{\circ} \mathrm{C}$. Nevertheless, hydrogen bonding or other weak interactions between silicate microparticles and cellulose fibers' surface were strong enough to provide good hydrophobic properties even after long contact with water. 


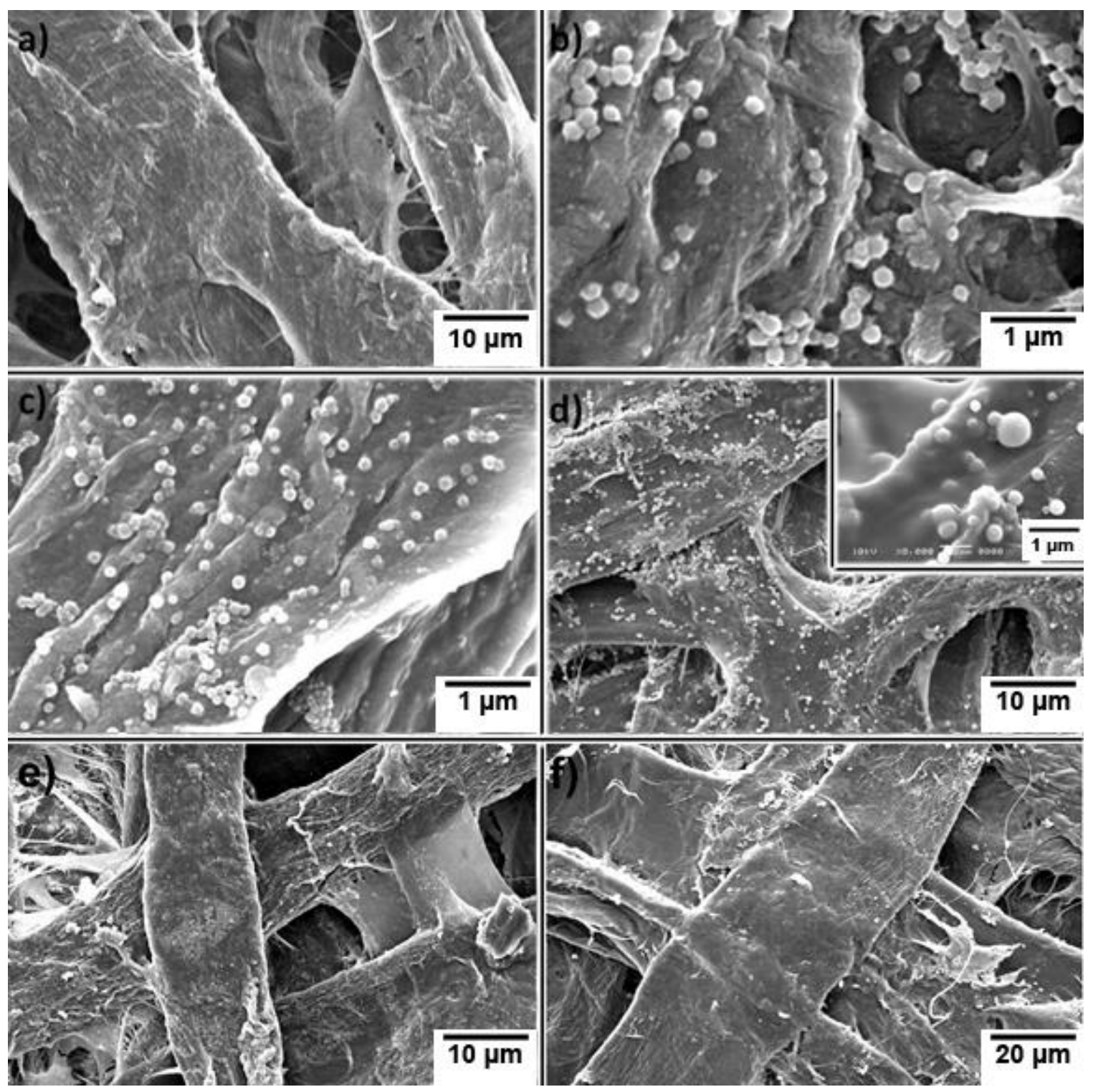

Fig. 3. SEM images of (a) the reference, untreated sample; (b and c) samples coated with starchsiloxane mixture ST:SIL 100:25; (d) a sample coated with ST:SIL 100:50; e) sample coater with ST 100 and f) sample coated with SIL 100.

Table 4. Chemical Composition of Dry Starch Isolated from the Samples

\begin{tabular}{|c|c|c|c|c|}
\hline Component & $\begin{array}{c}\text { Native Starch } \\
\text { (wt\%) }\end{array}$ & $\begin{array}{c}\text { Starch Mixture } \\
\text { (ST) (wt\%) }\end{array}$ & $\begin{array}{c}\text { Coating Mixture } \\
\text { ST:SIL 100:10 } \\
\text { (wt\%) }\end{array}$ & $\begin{array}{c}\text { Coating Mixture } \\
\text { ST:SIL 100:100 } \\
\text { (wt\%) }\end{array}$ \\
\hline Lipids & $0.24 \pm 0.02$ & $0.23 \pm 0.02$ & $0.24 \pm 0.02$ & $0.24 \pm 0.02$ \\
\hline Proteins & $0.29 \pm 0.01$ & $0.30 \pm 0.01$ & $0.30 \pm 0.01$ & $0.29 \pm 0.01$ \\
\hline Amylose & $31.16 \pm 0.15$ & $31.65 \pm 0.19$ & $31.42 \pm 0.19$ & $31.73 \pm 0.19$ \\
\hline
\end{tabular}

However, the nature of the bonds between the silicate particles and the paper surface requires further research, using X-ray photoelectron spectroscopy or similar methods. 


\section{Effect of Hydrophobizing Agents on the Mechanical Properties of the Paper}

Any chemical processing used during the production of paper should not adversely affect the mechanical properties of the product. Therefore, the most important mechanical properties of the hydrophobized handsheets were examined and compared with the reference samples.

Figure 4 illustrates differences in the tensile indices of the tested samples. The addition of both pure starch solution (ST) and pure siloxane emulsion (SIL) increased the tensile index. However, with the siloxane hydrophobizate, it was increased by $5 \mathrm{~N} \cdot \mathrm{m} / \mathrm{g}$, while with the starch solution it was increased by only $2.5 \mathrm{~N} \cdot \mathrm{m} / \mathrm{g}$, in comparison to the reference, untreated paper. Of the starch solution-hydrophobizate mixtures, the best effect was observed with the ST:SIL 100:10 samples (an increase of approximately $7 \mathrm{~N} \cdot \mathrm{m} / \mathrm{g}$ in comparison to the reference). For samples coated with starch-silicone mixtures of different proportions, the effect was less pronounced. The differences in tensile index between samples treated with the starch-siloxane mixtures and the paper coated with pure starch solution were low enough $( \pm 10 \%)$ to conclude that the hydrophobization agent did not diminish the tensile strength of the examined samples.

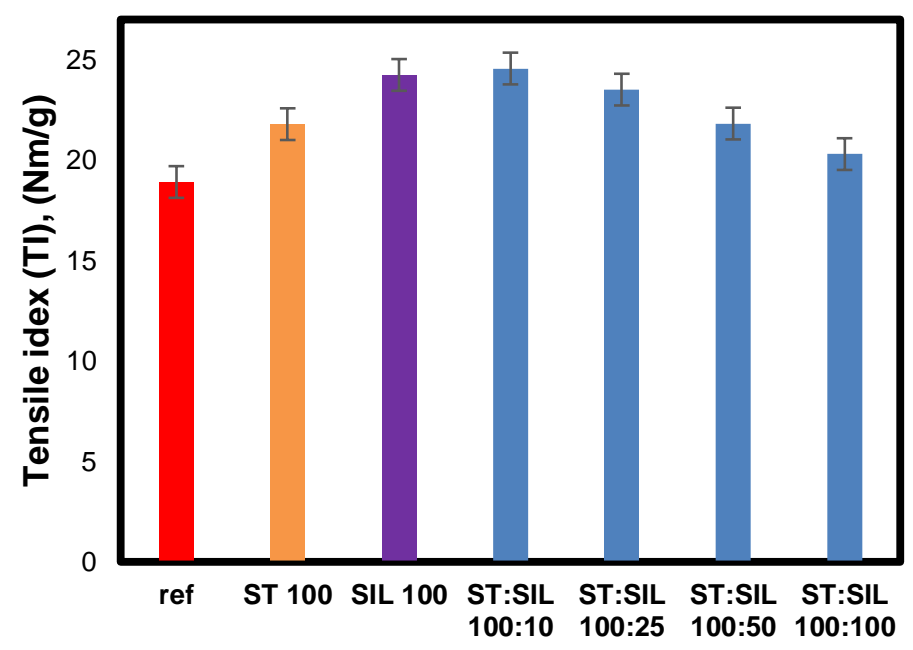

Fig. 4. Comparison of tensile index values of coated and reference samples; ref = reference

Tear resistance (Fig. 5) was the second examined mechanical parameter. All the samples coated with the starch-siloxane mixtures (ST:SIL) exhibited slightly decreased tear resistance indices compared to the reference, untreated paper. However, the negative effect did not exceed 3\% in comparison either to the untreated reference or to the paper coated with starch only, and it was within the limits of measurement error. Thus, it seemed reasonable to hypothesize that the preparations had no appreciable negative impact on tear resistance. 


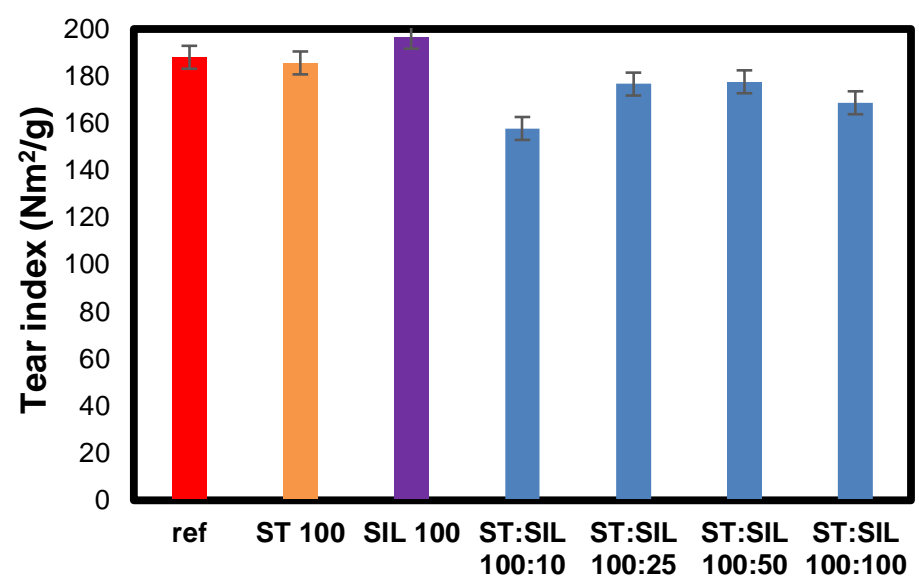

Fig. 5. Comparison of Elmendorf tear resistance index values of coated and reference samples; ref $=$ reference

\section{Surface Properties}

To be suitable for use in industrial production, any coating mixture should not substantially change the product's color, especially for white paper. Comparative analysis of the ISO brightness of the reference and modified samples showed that starch had a much greater influence on this parameter than the silane/siloxane hydrophobizate. The ISO brightness of samples coated with pure starch solution (ST) was 1.07, while that of paper coated with pure siloxane hydrophobizate (SIL) was 1.125, compared to 1.2 for the untreated, reference paper. The ISO brightness of the samples coated with starchsilane/siloxane emulsion (ST:SIL) were closer to that of paper treated with starch than to the reference sample. An increase from 1.08 to 1.1 in ISO brightness was also observed with increasing amount of silane/siloxane emulsion (Fig. 6).

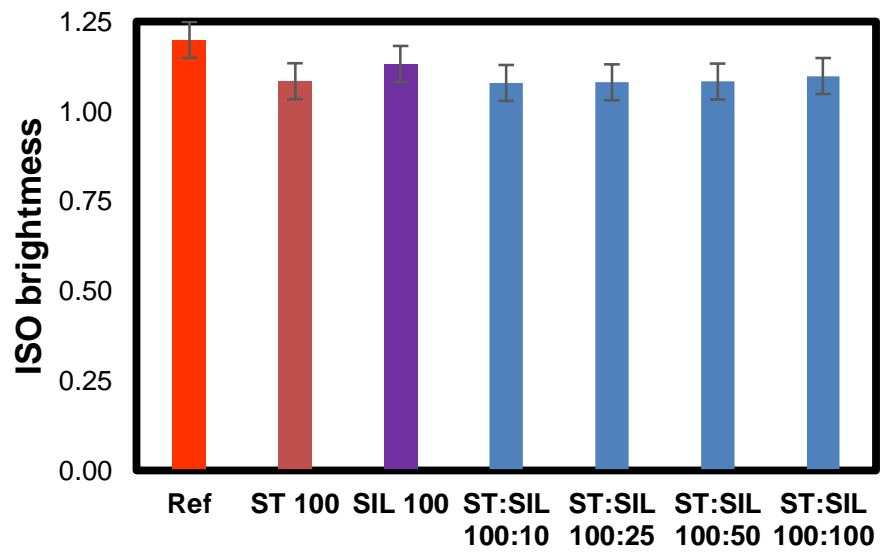

Fig. 6. ISO brightness values of coated and reference samples; Ref $=$ reference

The coating of the handsheets seemed to have a more predictable and additive pattern of influence on the surface roughness of the paper than on its mechanical properties. The paper coated with starch only (ST) showed an increase in roughness from 151.7 $\mathrm{mL} / \mathrm{min}$ to $158.5 \mathrm{~mL} / \mathrm{min}$, in comparison with the reference sample, while the paper coated with pure silane/siloxane hydrophobizate had $15 \%$ greater roughness. A quite simple, proportional relationship between the increasing roughness and the amount of 
silane/siloxane hydrophobizate in the mixture was observed for the paper samples coated with the starch-silane/siloxane mixtures (ST:SIL) (Fig. 7).

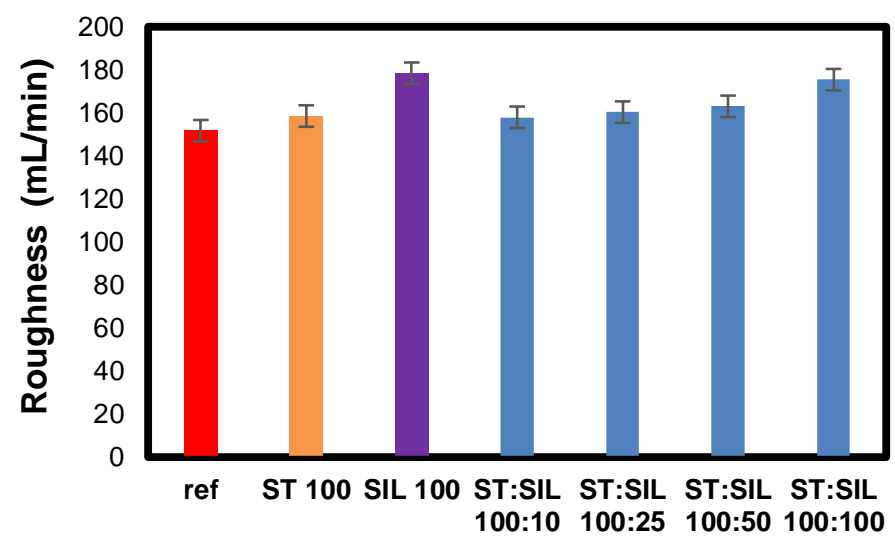

Fig. 7. Bendtsen surface roughness values of coated and reference samples; ref = reference

Figure 8 illustrates the influence of the coating agents on the air permeance of the handsheets. Modification of the paper both with starch only (ST) and with pure silane/siloxane hydrophobizate (SIL) notably decreased this parameter, in comparison to the reference sample. However, a much greater effect was observed with the starch solution. The samples coated with the starch-silane/siloxane mixtures (ST:SIL) exhibited air permeances similar to that of the paper treated with starch only (ST), irrespective of how much hydrophobizate was present in the mixture.

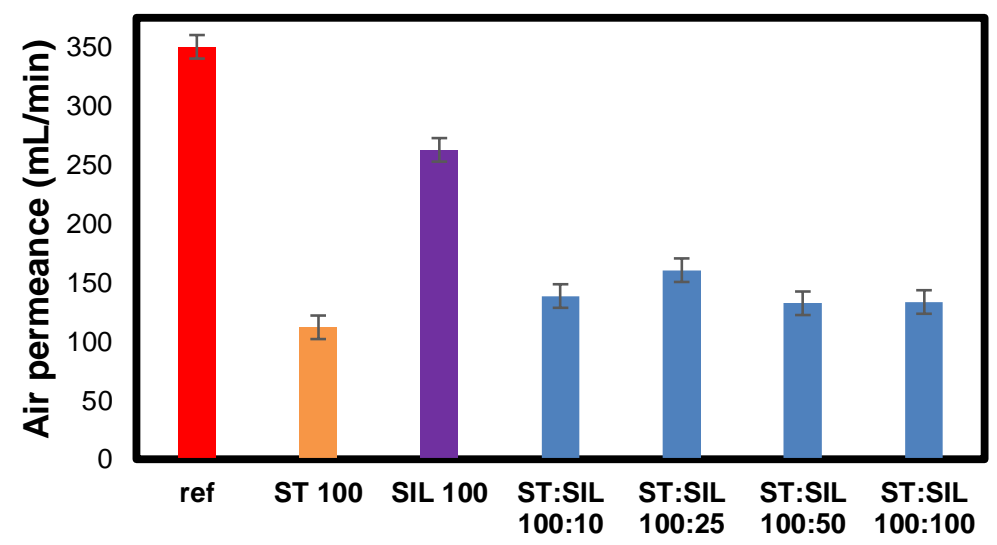

Fig. 8. Bendtsen air permeance values of coated and reference samples; ref = reference

Notably, despite the high levels of hydrophobicity obtained, all the coated paper samples retained non-zero air permeance, indicating that the pores on the surface and throughout the whole structure were still partially open. The hydrophobized paper could therefore still be considered a breathable material. This conclusion was supported by the SEM investigations of the surfaces of the samples, which showed the formation of silicate microparticles due to the self-condensation of triethoxymethylsilane and derivative oligomers (Fig. 3). 


\section{CONCLUSIONS}

1. This study presented a novel method of paper hydrophobization using a new low-cost silicone system based on an emulsion of triethoxymethylsilane in water mixed in a low concentration with a water solution of starch.

2. Satisfactory hydrophobicity (with a water contact angle greater than $90^{\circ}$ ) could be achieved even with $10 \mathrm{wt} \%$ of initial triethoxymethylsilane in $4 \mathrm{wt} \%$ starch water solution. The greatest hydrophobization (with a water contact angle greater than $100^{\circ}$ ) was obtained using starch/siloxane mixtures. A coating based on an aqueous triethoxymethylsilane solution without starch resulted in decreased contact angles and decreased resistance to water.

3. The application of the developed system using the Mayer rod coating method provided hydrophobic properties with no surface color changes while also preserving basic mechanical properties such as tensile strength and tear resistance.

4. Furthermore, the hydrophobized paper samples indicated non-zero air permeance, which qualified them as a breathable material. An increase in the roughness of the coated paper surfaces was also observed.

5. Solid state NMR and SEM studies were used to investigate the interactions between the silicone agent and starch/cellulose. Preliminary results suggested that the molecular mechanism of hydrophobization relied on the self-condensation of alkoxysilanes, leading to the deposition of silica microparticles on the surface of the paper and within the pores, rather than on a direct reaction between silanols and starch or cellulose.

6. Although, the nature of bonding between silica microparticles and cellulose fibers was not studied in detail, one can conclude that these bondings were strong enough to provide permanent hydrophobicity of paper.

\section{REFERENCES CITED}

AACC 46-12.01 (1983). "Crude protein -- Kjeldahl method, borid acid modification," American Association of Cereal Chemists, St. Paul, MN, USA.

Abdelmouleh, M., Boufi, S., ben Salah, A., Belgacem, M. N., and Gandini, A. (2002). "Interaction of silane coupling agents with cellulose," Langmuir 18(8), 3203-3208. DOI: $10.1021 / \mathrm{la} 011657 \mathrm{~g}$

Au, C. O., and Thorn, I. (eds.) (1995). Applications of Wet-End Paper Chemistry, Springer, Dordrecht, The Netherlands. DOI: 10.1007/978-94-017-0756-5

Cappelletto, E., Callone, E., Campostrini, R., Girardi, F., Maggini, S., della Volpe, C., Siboni, S., and Di Maggio, R. (2012). "Hydrophobic siloxane paper coatings: The effect of increasing methyl substitution," Journal of Sol-Gel Science and Technology 62(3), 441-452. DOI: 10.1007/s10971-012-2747-1

Castellano, M., Gandini, A., Fabbri, P., and Belgacem, M. N. (2004). "Modification of cellulose fibres with organosilanes: Under what conditions does coupling occur?," Journal of Colloid and Interface Science 273(2), 505-511. DOI: 10.1016/j.jcis.2003.09.044

Coatings2Go. (2014). "Hydrophobic Silicone Coating Safety Data Sheet 1012," (https://coatings2go.com/wp/wp-content/uploads/2012/06/hydrophobicsilicon_n.pdf). 
Despond, S., Espuche, E., Cartier, N., and Domard, A. (2005). "Barrier properties of paper-chitosan and paper-chitosan-carnauba wax films," Journal of Applied Polymer Science 98(2), 704-710. DOI: 10.1002/app.21754

Goussé, C., Chanzy, H., Excoffier, G., Soubeyrand, L., and Fleury, E. (2002). "Stable suspensions of partially silylated cellulose whiskers dispersed in organic solvents," Polymer 43(9), 2645-2651. DOI: 10.1016/S0032-3861(02)00051-4

Han, J. H., and Krochta, J. M. (2001). "Physical properties and oil absorption of wheyprotein-coated paper," Journal of Food Science 66(2), 294-299. DOI: 10.1111/j.13652621.2001.tb11335.x

Holik, H. (ed.) (2013). Handbook of Paper and Board: Second, Revised and Enlaged Edition, Wiley-VCH Verlag GmbH \& Co. KGaA, Weinheim, Germany. DOI: $10.1002 / 9783527652495$

Hubbe, M. A. (2007). "Paper's resitance to wetting - A review of internal sizing chemicals and their effects," BioResources 2(1), 106-145.

ISO 187 (1990). "Paper, board and pulps — Standard atmosphere for conditioning and testing and procedure for monitoring the atmosphere and conditioning of samples," International Organization for Standardization, Geneva, Switzerland.

ISO 1924-2 (2008). "Paper and board - Determination of tensile properties - Part 2: Constant rate of elongation method $(20 \mathrm{~mm} / \mathrm{min})$," International Organization for Standardization, Geneva, Switzerland.

ISO 1974 (1990). "Paper — Determination of tearing resistance (Elmendorf method)," International Organization for Standardization, Geneva, Switzerland.

ISO 2470-1 (2016). "Paper, board and pulps - Measurement of diffuse blue reflectance factor - Part 1: Indoor daylight conditions (ISO brightness)," International Organization for Standardization, Geneva, Switzerland.

ISO 5636-3 (1992). "Paper and board - Determination of air permeance (medium range) — Part 3: Bendtsen method," International Organization for Standardization, Geneva, Switzerland.

ISO 8791-2 (1990). "Paper and board - Determination of roughness/smoothness (air leak methods) - Part 2: Bendtsen method," International Organization for Standardization, Geneva, Switzerland.

ISO 535 (2014). "Paper and board - Determination of water absorptiveness - Cobb method," International Organization for Standardization, Geneva, Switzerland.

Khanjanzadeh, H., Behrooz, R., Bahramifar, N., Gindl-Altmutter, W., Bacher, M., Edler, M., and Griesser, T. (2018). "Surface chemical functionalization of cellulose nanocrystals by 3-aminopropyltriethoxysilane," International Journal of Biological Macromolecules 106, 1288-1296. DOI: 10.1016/j.ijbiomac.2017.08.136

Korhonen, J. T., Kettunen, M., Ras, R. H. A., and Ikkala, O. (2011). "Hydrophobic nanocellulose aerogels as floating, sustainable, reusable, and recyclable oil absorbents," ACS Applied Materials \& Interfaces 3(6), 1813-1816. DOI: 10.1021/am200475b

Kurjata, J., Rozga-Wijas, K., and Stanczyk, W. (2013). Investigation of hydrolysis and condensation of methyltriethoxysilane in aqueous systems," European Journal of Chemistry 4(4), 343-349. DOI: 10.5155/eurjchem.4.4.343-349.835

Kurjata, J., Rozga-Wijas, K., and Stańczyk, W. (2018) "Sposób wytwarzania alkoksysilanów, mieszanina hydrofobizująco- modyfikująca oraz jej sposób wytwarzania", Polish Patent. PL 228194

Laitinen, O., Suopajärvi, T., Österberg, M., and Liimatainen, H. (2017). "Hydrophobic, 
superabsorbing aerogels from choline chloride-based deep eutectic solvent pretreated and silylated cellulose nanofibrils for selective oil removal," ACS Applied Materials \& Interfaces 9(29), 25029-25037. DOI: 10.1021/acsami.7b06304

Le, D., Kongparakul, S., Samart, C., Phanthong, P., Karnjanakom, S., Abudula, A., and Guan, G. (2016). "Preparing hydrophobic nanocellulose-silica film by a facile onepot method," Carbohydrate Polymers 153, 266-274. DOI:

10.1016/j.carbpol.2016.07.112

Lindström, T., and Larsson, P. T. (2008). "Alkyl ketene dimer (AKD) sizing - A review," Nordic Pulp \& Paper Research Journal 23(2), 202-209. DOI: 10.3183/NPPRJ-200823-02-p202-209

Luna Marroquin, N., Severiano Perez, O., Gutierrez Antonio, J., Pamanes Bringas, R., De Haene Rosique, G. J., and Gomez Cordon, J. (2015). "Hydrophobic paper or cardboard with self-assembled nanoparticles and method for the production thereof," European Patent EP 2837736 A1

Missoum, K., Belgacem, M. N., and Bras, J. (2013). "Nanofibrillated cellulose surface modification: A review," Materials 6(5), 1745-1766. DOI: 10.3390/ma6051745

Morrison, W. R., and Laignelet, B. (1983). "An improved colorimetric procedure for determining apparent and total amylose in cereal and other starches," Journal of Cereal Science 1(1), 9-20. DOI: 10.1016/S0733-5210(83)80004-6

Musso, G. E., Bottinelli, E., Celi, L., Magnacca, G., and Berlier, G. (2015). "Influence of surface functionalization on the hydrophilic character of mesoporous silica nanoparticles," Physical Chemistry Chemical Physics 17(21), 13882-13894. DOI: 10.1039/C5CP00552C

Ogihara, H., Xie, J., Okagaki, J., and Saji, T. (2012). "Simple method for preparing superhydrophobic paper: Spray-deposited hydrophobic silica nanoparticle coatings exhibit high water-repellency and transparency," Langmuir 28(10), 4605-4608. DOI: 10.1021/la204492q

Oyola-Reynoso, S., Tevis, I. D., Chen, J., Chang, B. S., Çinar, S., Bloch, J.-F., and Thuo, M. M. (2016). "Recruiting physisorbed water in surface polymerization for bioinspired materials of tunable hydrophobicity," Journal of Materials Chemistry A 4(38), 14729-14738. DOI: 10.1039/C6TA06446A

Oyola-Reynoso, S., Wang, Z., Chen, J., Çınar, S., Chang, B., and Thuo, M. (2015). "Revisiting the challenges in fabricating uniform coatings with polyfunctional molecules on high surface energy materials," Coatings 5(4), 1002-1018. DOI: 10.3390/coatings5041002

Pei, A., Zhou, Q., and Berglund, L. A. (2010). "Functionalized cellulose nanocrystals as biobased nucleation agents in poly(l-lactide) (PLLA) - Crystallization and mechanical property effects," Composites Science and Technology 70(5), 815-821. DOI: 10.1016/j.compscitech.2010.01.018

Rosicka - Kaczmarek, J., Makowski, B., Nebesny, E., Tkaczyk, M., Komisarczyk, A., and Nita, Z. (2016). "Composition and thermodynamic properties of starches from facultative wheat varieties," Food Hydrocolloids 54, 66-76. DOI:

10.1016/j.foodhyd.2015.09.014

Rózga-Wijas, K., Fortuniak, W., Kowalewska, A., and Chojnowski, J. (2010). "Generation of 3-chloropropylsilanetriol: Monomer for the synthesis of 3chloropropyl substituted oligosilsesquioxanes," Journal of Inorganic and Organometallic Polymers and Materials 20(2), 387-394. DOI: 10.1007/s10904-0109351-z 
Rutter, T., and Hutton-Prager, B. (2018). "Investigation of hydrophobic coatings on cellulose-fiber substrates with in-situ polymerization of silane/siloxane mixtures," International Journal of Adhesion and Adhesives 86, 13-21. DOI: 10.1016/j.ijadhadh.2018.07.008

Saini, S., Belgacem, M. N., Salon, M.-C. B., and Bras, J. (2016). 'Non leaching biomimetic antimicrobial surfaces via surface functionalisation of cellulose nanofibers with aminosilane," Cellulose 23(1), 795-810. DOI: 10.1007/s10570-0150854-1

Samyn, P. (2013). "Wetting and hydrophobic modification of cellulose surfaces for paper applications," Journal of Materials Science 48(19), 6455-6498. DOI: 10.1007/s10853-013-7519-y

Song, J., and Rojas, O. J. (2013). "Approaching super-hydrophobicity from cellulosic materials: A review," Nordic Pulp \& Paper Research Journal 28(2), 216-238. DOI: 10.3183/NPPRJ-2013-28-02-p216-238

Stańczyk, W., Kurjata, J., Wijas, K., Lefik, M., Wojciechowski, M., and Baryła, P. (2018). "Sposób wytwarzania alkoksysilanów, mieszanina hydrofobizującomodyfikująca oraz sposób jej wytwarzania," Polish Patent No. 228194.

TAPPI T 458 (2004). "Surface wettability of paper (angle of contact method)," TAPPI Press, Atlanta, GA, USA.

Wei, B., Sun, B., Zhang, B., Long, J., Chen, L., and Tian, Y. (2016). "Synthesis, characterization and hydrophobicity of silylated starch nanocrystal," Carbohydrate Polymers 136, 1203-1208. DOI: 10.1016/j.carbpol.2015.10.025

Wojciechowski, M., Baryła, P., and Lefik, M. (2014). "Main properties of sands hydrophobized by alkoxysilane emulsions," Acta Geophysica 62(5), 1192-1201. DOI: 10.2478/s11600-014-0223-8

Xie, Y., Hill, C. A. S., Xiao, Z., Militz, H., and Mai, C. (2010). "Silane coupling agents used for natural fiber/polymer composites: A review," Composites Part A: Applied Science and Manufacturing 41(7), 806-819. DOI: 10.1016/j.compositesa.2010.03.005

Xu, Y., Hartong, B. H., and Deng, Y. (2002). "Neutral to alkaline rosin sizing using polyethyleneimine-epichlorohydrin (PEI-epi) as a mordant," Journal of Pulp and Paper Science 28(2), 39-44.

Article submitted: November 1, 2019; Peer review completed: February 13, 2020; Revised version received and accepted: April 1, 2020; Published: April 10, 2020. DOI: 10.15376/biores.15.2.4124-4142 